\title{
Compliance of Parties to the Kyoto Protocol in the first Commitment Period
}

Climate Policy, 16 (6), pp.768-782

\section{Authors}

- Igor Shishlov, I4CE - Institute for Climate Economics, Paris, FR, igor.shishlov@i4ce.org

- Romain Morel, I4CE - Institute for Climate Economics, Paris, FR, romain.morel@i4ce.org

- INRA, UMR1041 CESAER, Université Bourgogne Franche-Comté, AgroSup Dijon, F21000 Dijon, France, valentin.bellassen@dijon.inra.fr

\section{Abstract}

This article provides an ex-post analysis of compliance of parties to the Kyoto Protocol during the CP1 (2008-2012) based on the final data on national greenhouse gas (GHG) emissions and exchanges in carbon units that became available at the end of 2015. The analysis shows that among the 36 countries that fully participated to the CP1, only nine countries emitted higher levels of GHGs than committed under the Kyoto Protocol and therefore had to resort to flexibility mechanisms. Countries implemented different compliance strategies: purchasing carbon units abroad, stimulating the domestic use of carbon credits by the private sector and incentivizing domestic emission reductions through climate policies. While countries party to the Protocol largely surpassed their aggregate commitment by $2.4 \mathrm{Gt} \mathrm{CO}_{2} \mathrm{e}$ per annum, the bulk of this overachievement is due to an estimated $2.2 \mathrm{Gt} \mathrm{CO}_{2} \mathrm{e}$ per annum of "hot air" - or the emission reductions that already occurred in economies in transition before 1997. The participation of the USA and Canada would have added a net $1 \mathrm{Gt} \mathrm{CO}_{2} \mathrm{e}$ per annum of overshoot and LULUCF accounting rules further removed $0.4 \mathrm{Gt} \mathrm{CO}_{2} \mathrm{e}$ per annum from the net result excluding LULUCF. None of these factors, some of which can be deemed illegitimate, would therefore on its own have led to global non-compliance, even without use of the $0.3 \mathrm{Gt} \mathrm{CO}_{2} \mathrm{e}$ of emissions reductions generated per annum by the CDM. The impact of domestic policies and "carbon leakage" neither of them quantitatively assessed here - should not be neglected either.

\section{Policy relevance}

Given the ongoing evolution of the international climate regime and the adoption of the Paris Agreement in December 2015, we believe that there is a need to evaluate the results of the first Commitment Period of the Kyoto Protocol. To our knowledge there has been no synthetic quantitative ex-post assessment of the Kyoto Protocol based on the final emissions data for 2008-2012 that became available in late-2015. This article attempts to fill this gap focusing on domestic and international compliance of the Parties to the Protocol in the CP1.

Key words: Kyoto Protocol; Greenhouse Gas Emissions; Emissions Trading; Carbon Accounting. 


\section{Introduction}

The Kyoto Protocol, adopted in 1997, established greenhouse gas (GHG) emissions reduction targets for 38 developed countries and economies in transition (EIT) - Annex B parties to the Protocol. These mitigation targets were enounced in countries' emissions allowances Assigned Amount Units (AAU). In order to maximize the economic efficiency of achieving their targets, parties were allowed to exchange AAUs and to use carbon credits resulting from emissions reduction projects - Joint Implementation (JI) in Annex B countries and the Clean Development Mechanism (CDM) in non-Annex B countries.

The first Commitment Period (CP1) under the Kyoto Protocol ended on 31 December 2012. In April 2014, Annex B countries submitted their final GHG emissions data. By 10 July 2015, all of these data had been reviewed and therefore truly finalized. Trading of units under the Kyoto Protocol was allowed until the end of the so-called "true-up period" on 18 November 2015. Data covering the use of units during this period is available and is planned to be reviewed by February 2016 with aggregated final data expected by April 2016. Although this trading data is not truly final, coherences checks and the accumulated experience of last years makes expect small variations with currently available data. It is therefore possible to conduct an ex-post assessment of the results of the CP1 of the Kyoto Protocol, which is the main objective of this article.

There have been hundreds of studies related to the Kyoto Protocol and its flexibility mechanisms. The key research topics included among others: the history of the Kyoto Protocol and the CDM (Bolin 2008 and Lecocq and Ambrosi 2007 respectively), ex-ante assessments of the Kyoto Protocol's economic costs (e.g. Weyant and Hill 1999; Nordhaus and Boyer 1999) and environmental impacts (e.g. Barrett 1998), analysis of the performance of the CDM (Castro and Michaelowa 2008; Wara and Victor 2008; Schneider 2009; Haya 2009; Shishlov and Bellassen 2012) and JI (Zhenchuk 2012; Shishlov, Bellassen, and Leguet 2012; Kollmuss, Schneider, and Zhezherin 2015), the use of Kyoto units under the European Union's Emissions Trading System (EU ETS, Stephan, Bellassen, and Alberola 2014), carbon accounting in the CDM (Warnecke 2014; Shishlov and Bellassen 2015) and its contribution to sustainable development (Schneider 2007; Gupta et al. 2008; Boyd et al. 2009; Haya and Parekh 2011), to name only a few. 
To our knowledge, however, there has been no synthetic quantitative ex-post assessment of the Kyoto Protocol based on the final emissions and trading data of the CP1. Even true-up reports do not show a readable analysis of individual and aggregated strategies to comply. This article thus attempts to fill this gap. The research methodology is primarily based on the analysis of publicly available primary data sources (UNFCCC databases, UNEP DTU CDM/JI Pipeline, International Transaction Log, etc.). UNFCCC legal documents and a literature review are used to interpret the quantitative findings.

The rest of the article is structured as follows. Section 2 reviews the domestic emissions reductions of Annex B countries with their respective emissions reduction targets. Section 3 reviews the international compliance by analyzing the use of the Kyoto flexibility mechanisms by Parties. Finally, Section 4 draws conclusions on the results of the CP1 of the Kyoto Protocol.

\section{Domestic emissions reductions of the Parties to the Kyoto Protocol}

Under the Kyoto Protocol, thirty-eight countries - hereafter called "Annex B-1997 countries $^{\prime 1}$ - accounting for $39 \%$ of 2010 global GHG emissions - committed to a $5 \%$ decrease of their emissions between 2008 and 2012 in comparison with their base-year emissions - most often 1990 (see Appendix). With the non-ratification of the Kyoto Protocol by the USA and the withdrawal of Canada in 2011, the commitment of the 36 remaining countries - hereafter called "Annex B-2012 countries" - accounting for $24 \%$ of global GHG emissions in 2010 - was equivalent to a $4 \%$ decrease of their emissions.

\subsection{Most countries reduced their emissions more than required by the Protocol}

In April 2014, Annex B countries submitted their final emissions data for the CP1. By 10 July 2015, all of these data have been reviewed and therefore truly finalized. These data shows that among the thirty-six countries that fully participated to the CP1 of the Kyoto Protocol, only nine countries - Austria, Denmark, Iceland, Japan, Lichtenstein, Luxembourg, Norway, Spain and Switzerland - emitted higher levels of GHGs than committed under the Kyoto Protocol including Land-Use, Land-Use Change and Forestry (LULUCF) emissions and sinks

\footnotetext{
${ }^{1}$ See the appendix for a detailed list of countries.
} 
(Figure 1). While these countries represented 20\% of emissions of Annex B-2012 countries

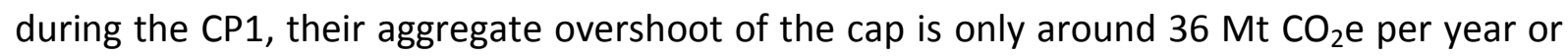
less than 1\% of Annex B-2012 countries average annual emissions during the CP1. In order to comply with their commitments under the Protocol, these countries therefore had to resort to flexibility mechanisms (see Section 3).

Figure 1 - Absolute difference between the average annual emissions of Annex B-2012 countries in 2008-2012 and their respective Kyoto targets including LULUCF (in $\mathrm{MtCO}_{2} \mathrm{e}$ )

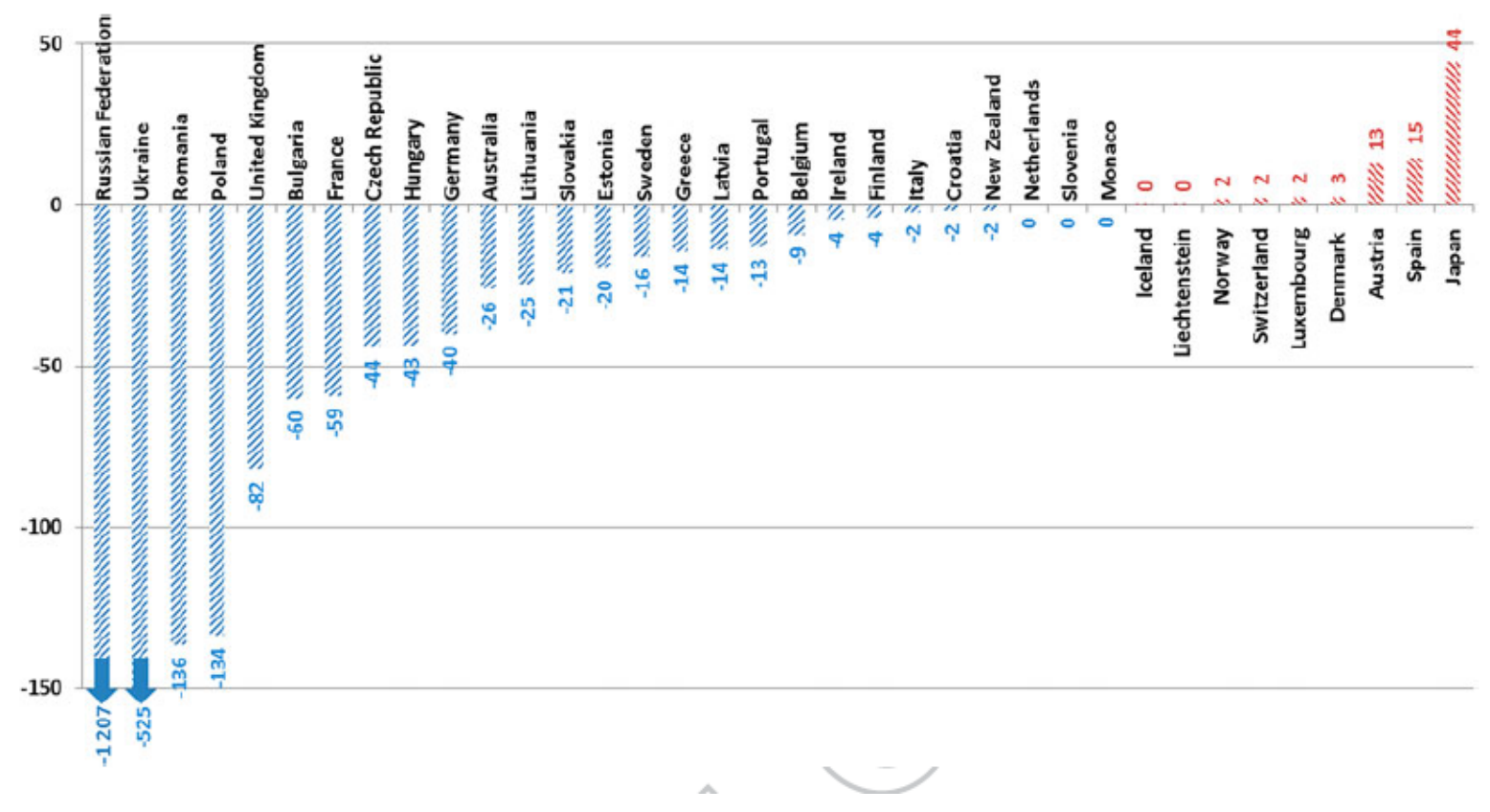

Source: authors' calculations based on the final annual review reports as published by the UNFCCC on 10 July 2015.

As to the relative difference between the average annual emissions of Annex B-2012 countries in 2008-2012 and their respective Kyoto targets, it can be observed that all economy-in-transition (EIT) countries reduced their emissions significantly more than committed (Figure 2). More specifically, all EITs except Croatia and Slovenia overreached their respective targets by more than $20 \% \mathrm{pt}^{2}$. At a broader level, the underachievement of some countries is more than offset by other countries. Indeed, the average annual aggregated GHG emissions of Annex B-2012 countries in 2008-2012 were 24\% below the base-year emissions, while their aggregate target was only $4 \%$ reduction: the overall Kyoto

\footnotetext{
${ }^{2}$ For example, Poland's target was $-6 \%$, and its average annual aggregated GHG emissions in 2008-2012 was $29.7 \%$ below base year. It therefore overreached its target by $29.7-6=23.7 \%$ pt.
} 
target has been overachieved by $2.4 \mathrm{Gt} \mathrm{CO}_{2} \mathrm{e}$. Detailed data on countries' GHG emissions during the CP1 is presented in the Appendix.

Figure 2 - Relative difference between the average annual emissions of Annex B-2012 countries in 2008-2012 and their respective Kyoto targets including LULUCF (in $\% \mathrm{pt}^{2}$ )

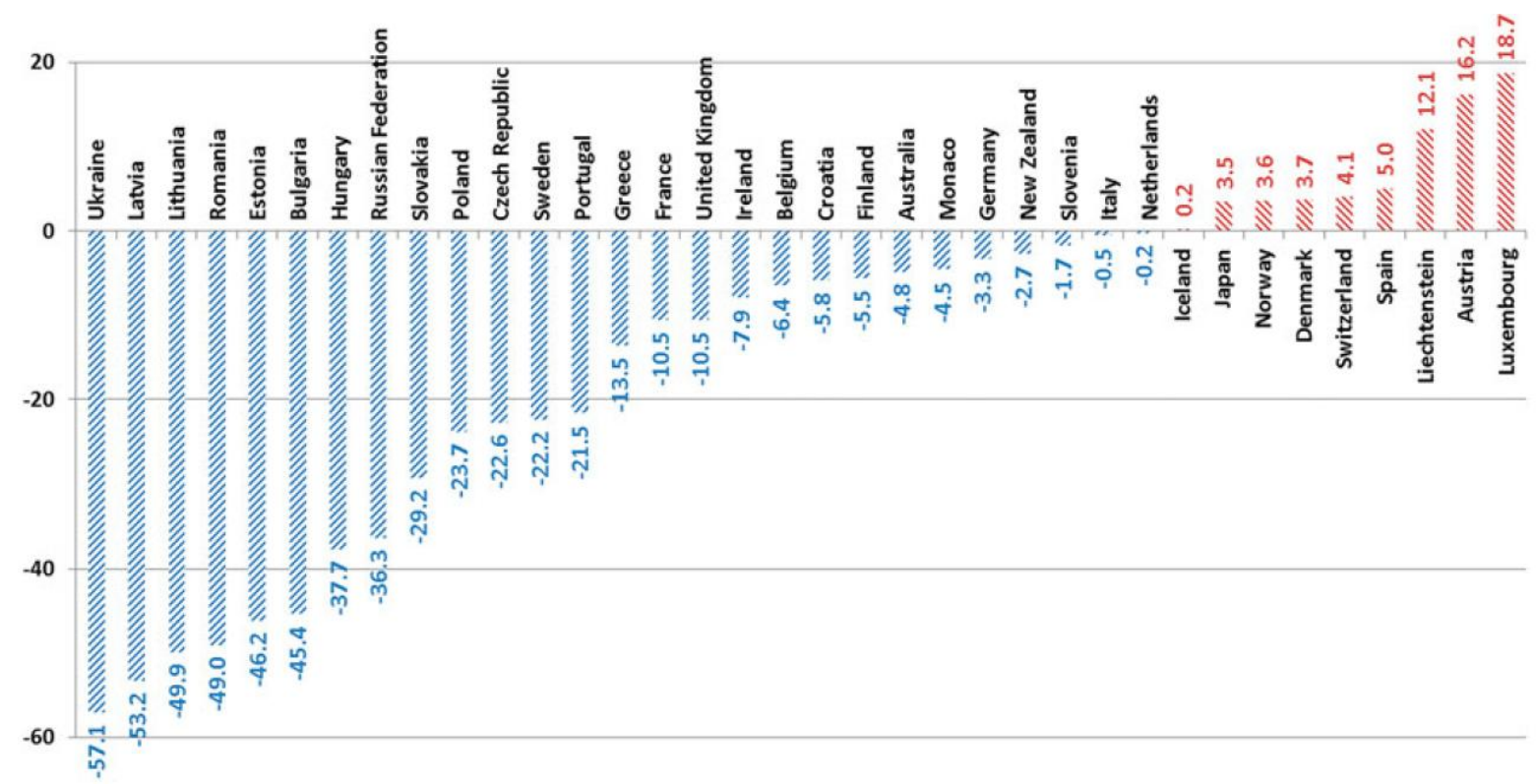

Source: authors' calculations based on the final annual review reports as published by the UNFCCC on 10 July

2015.

\subsection{Overall compliance would have been achieved even without "hot air"}

The collapse of the Soviet Union resulted in the rapid contraction of the economies of the Eastern Bloc. This in turn resulted in a large drop in GHG emissions of these countries compared to their respective base-year emissions - in most cases 1990. While the EIT countries started to recover in mid-1990s, their GHG emissions were still far below the baseyear during the CP1 (Figure 3). The resulting surplus of emissions allowances is often referred to as "hot air", as these emission reductions occurred before the adoption of the Kyoto Protocol in 1997.

The amount of "hot air" can be roughly estimated as the difference between base-year and 1997 emissions in EITs. This is coherent with the fact that the Kyoto Protocol was adopted around the time when the GDP of EITs started recovering. Using this simplified approach the

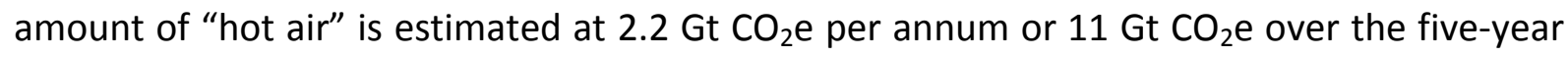
period of the CP1. Note that part of the emissions reductions that occurred in Germany can also be attributed to the restructuring of the East German economy following the 
reunification (Schleicha et al. 2001). These emissions reductions are not included in our estimate of "hot air".

In order to estimate the impact of "hot air" on the ambition of the Kyoto Protocol the annual emissions cap can be artificially adjusted by $2.2 \mathrm{Gt} \mathrm{CO}_{2} \mathrm{e}$. Even in this case, the overall target

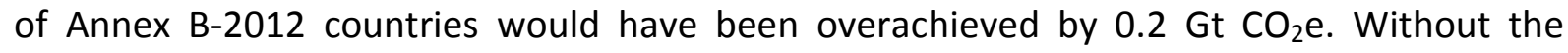
inclusion of LULUCF however (see Section 2.4), $0.15 \mathrm{Gt} \mathrm{CO}_{2} \mathrm{e}$ per year would have been missing to achieve the overall target (Figure 3). While not negligible, this deficit could be easily covered by carbon credits from developing countries created by the CDM (see Section 3.3).

Figure 3 - Evolution of Annex B-2012 absolute annual emissions excluding LULUCF*

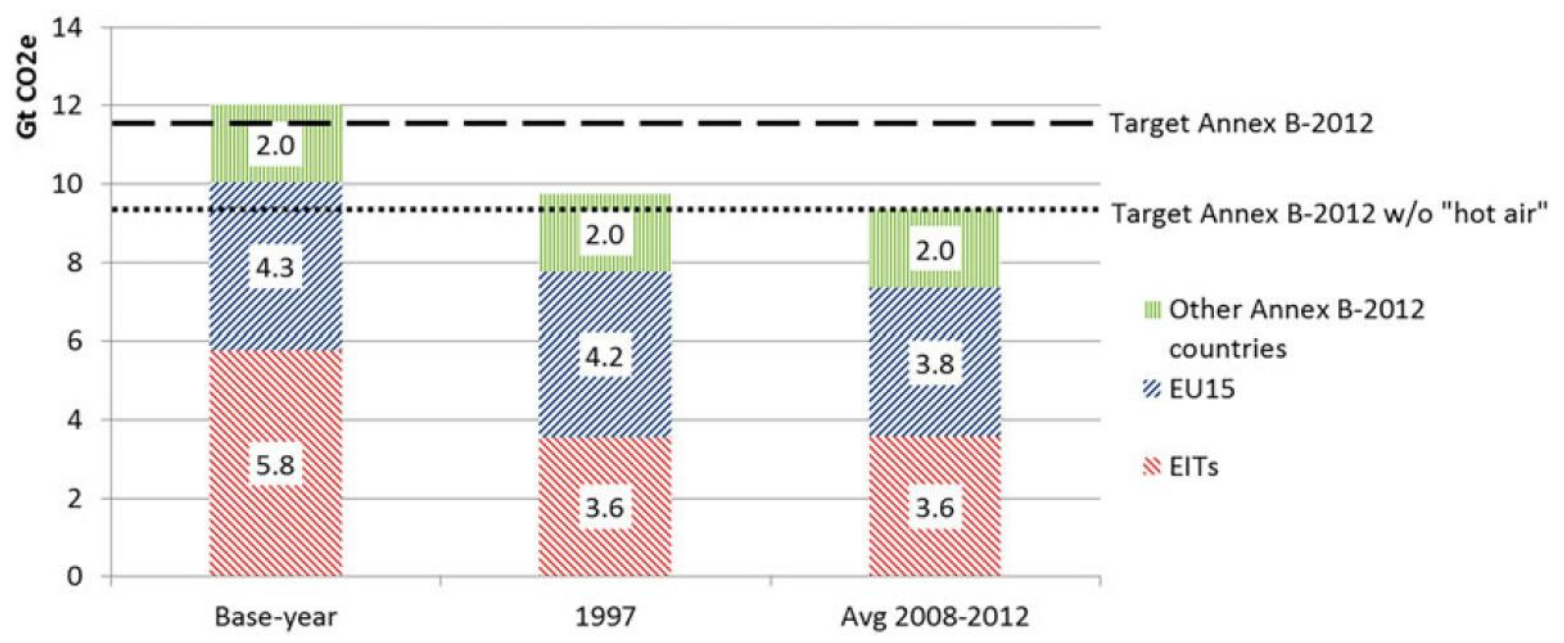

*Note: LULUCF is not included here as accountability rules only apply to the 2008-2012 period.

Source: authors' calculations based on the GHG emissions data as published by the UNFCCC on 10 July 2015.

\subsection{Factors explaining the overachievement of the overall Kyoto target}

The overachievement of the global Kyoto target in the CP1 can be explained by four main factors. The first two were already suggested by ex-ante studies that analyzed the potential impact of the Kyoto Protocol (Nordhaus and Boyer 1999; Böhringer 2000; Manne and Richels 2004), while the latter two naturally emerged in more recent research (Schiermeier 2012; Peters et al. 2012; Gloaguen and Alberola 2013):

(1) "Hot air" from the economies in transition;

(2) The non-participation of the USA and Canada;

(3) The global financial and economic crisis that decreased GHG emissions; 
(4) Policies and measures put in place by signatory countries.

While the "hot air" surplus was apparent back in 1997, it was expected to be balanced by the deficit of emissions allowances in the USA and by expected large economic recovery of EITs. Significant transfers of allowances between the USA and EITs were therefore expected (Nordhaus and Boyer 1999). Indeed, with the participation of North-American countries, Annex B-1997 countries still have a comfortable annual margin of $1.0 \mathrm{Gt} \mathrm{CO}_{2} \mathrm{e}$ excluding LULUCF. Nevertheless, in terms of compliance of individual countries, this would have required significant transfers of carbon allowances between parties, notably from EITs to the USA and Canada. At the same time, it was known back in 1997 that the Kyoto Protocol could enter into force without the ratification by the USA, while the late withdrawal of countries as it happened with Canada - was allowed.

Combining factors (1) and (2), i.e. adjusting the cap by the amount of "hot air" and including the USA and Canada, overall compliance with Kyoto targets would not have been achieved. Indeed, the deficit of emissions allowances, including LULUCF for all countries except USA and Canada would have been around $1.0 \mathrm{Gt} \mathrm{CO}_{2} \mathrm{e}$ annually, representing $5.1 \%$ of base-year emissions. Had North-American countries participated, the application of LULUCF accounting rules to their total would probably also have reduced this deficit. Moreover, they would probably have implemented tougher mitigation policies and financed more overseas emissions reductions, which would have further reduced this hypothetical compliance gap. In reality, however, both countries produced significantly higher emissions than their initial target.

Concerning factor (3), the total impact of the 2008-2009 crisis on the emissions of Annex B1997 countries was of comparable magnitude to the impact of the contraction of the EITs following the collapse of the Soviet Union. Between 2007 and 2009, annual emissions of Annex B-1997 countries declined by $1.5 \mathrm{Gt} \mathrm{CO}_{2} \mathrm{e}$. This amount is an upper estimate, as part of these emissions reductions may also be attributed to tougher national and regional climate policies. Indeed, within the scope of the EU ETS, the econometric analysis of Gloaguen and Alberola (2013) attributes more than half of emissions reductions to climate policies.

More generally, the World Bank (2014) reported that 39 national jurisdictions have implemented or are scheduled to implement carbon pricing instruments, including emissions 
trading systems and taxes. Amongst them, the EU ETS is the largest example of national policy incentivizing both domestic emission reductions and the use of Kyoto flexibility mechanisms. Moreover, many countries have put in place other climate policies such as energy efficiency measures or renewable energy support programs in order to incentivize private investments in emissions reductions.

While it is difficult to establish a direct causal link between the Kyoto Protocol and domestic climate policies, the political signal created by the international climate negotiations has likely boosted policies on national and regional levels. For example, the EU directive 2003/87/EC justifies the introduction of the EU ETS by the adoption of the Kyoto Protocol by the EU and its member states. Further evaluation of the impact of domestic policies on GHG emissions is outside the scope of this article.

A fifth factor has also been suggested as key to explain the overachievement of the global Kyoto target, namely "carbon leakage" due to the relocation of industrial activity from Annex 1 to non-Annex 1 Parties. Given that the verified national GHG inventory data on which the present assessment does not exist for non-Annex 1 countries, there is little we can add here to the existing literature on "carbon leakage". To our knowledge, this factor is not significant. Indeed, existing studies did not detect any significant impact of the EU ETS on the competitiveness of European industry (Branger et al., 2013; Ellerman et al., 2010; Sartor, 2012b). In addition, the Technology-adjusted Consumption-Based Accounting (TCBA) / Production-Based Accounting (PBA) emissions ratio underwent only minor changes over 1995-2009 for Annex B-2012 countries, suggesting the increase in low-carbon exports offset the increase in "imported emissions" (Kander et al. 2015) over the period.

\subsection{The impact of LULUCF accounting rules on domestic emissions}

When the Kyoto Protocol was signed in 1997, the accounting rules for LULUCF emissions were not finalized. Nevertheless, their inclusion in the Protocol was later enabled through the articles 3.3, 3.4 and 3.7:

- Article 3.4 allows countries to optionally include in their national inventories the carbon emissions and sequestration related to the management of forests, croplands and grasslands. In practice, this mainly concerns forests and includes all changes in the carbon stocks of lands that have been forests since 1990. The Kyoto Protocol caps 
the quantity of Removal Units (RMUs) that a country can receive from a positive "3.4 budget", in principle to factor out effects linked to the normal aging of forests and the acceleration of their growth because of climate change.

- Article 3.3 requires an accounting for emissions and sinks linked to reforestation and deforestation resulting in land use changes. The net variation between 2008 and 2012 of the carbon stock of these lands, the use of which has changed since 1990, constitutes the "3.3 budget".

- Article 3.7 only concerns countries, for which LULUCF was a net source of emissions in 1990. For these countries, net emissions from deforestation in 1990 are added to the base-year emissions, which translates into extra AAUs in proportion to the country's reduction target. This was intended to balance the expected deficit in the "3.3 budget" and create a net reward for reduced deforestation.

At the global level, emissions excluding LULUCF accounting decreased by $21.3 \%$ in Annex B2012 countries while emissions including these provisions decreased by $24.2 \%$. The impact of LULUCF accounting was thus beneficial for most countries, totaling net emissions reductions of $0.42 \mathrm{Gt} \mathrm{CO}_{2} \mathrm{e}$ (Figure 4). Approximately one-third of this figure comes from the application of Article 3.7 to Australia while another third is due to the application of Article 3.4 and to Russia. 
Figure 4 - Impact of LULUCF accounting (articles 3.3, 3.4 and 3.7) as \% of base-year emissions

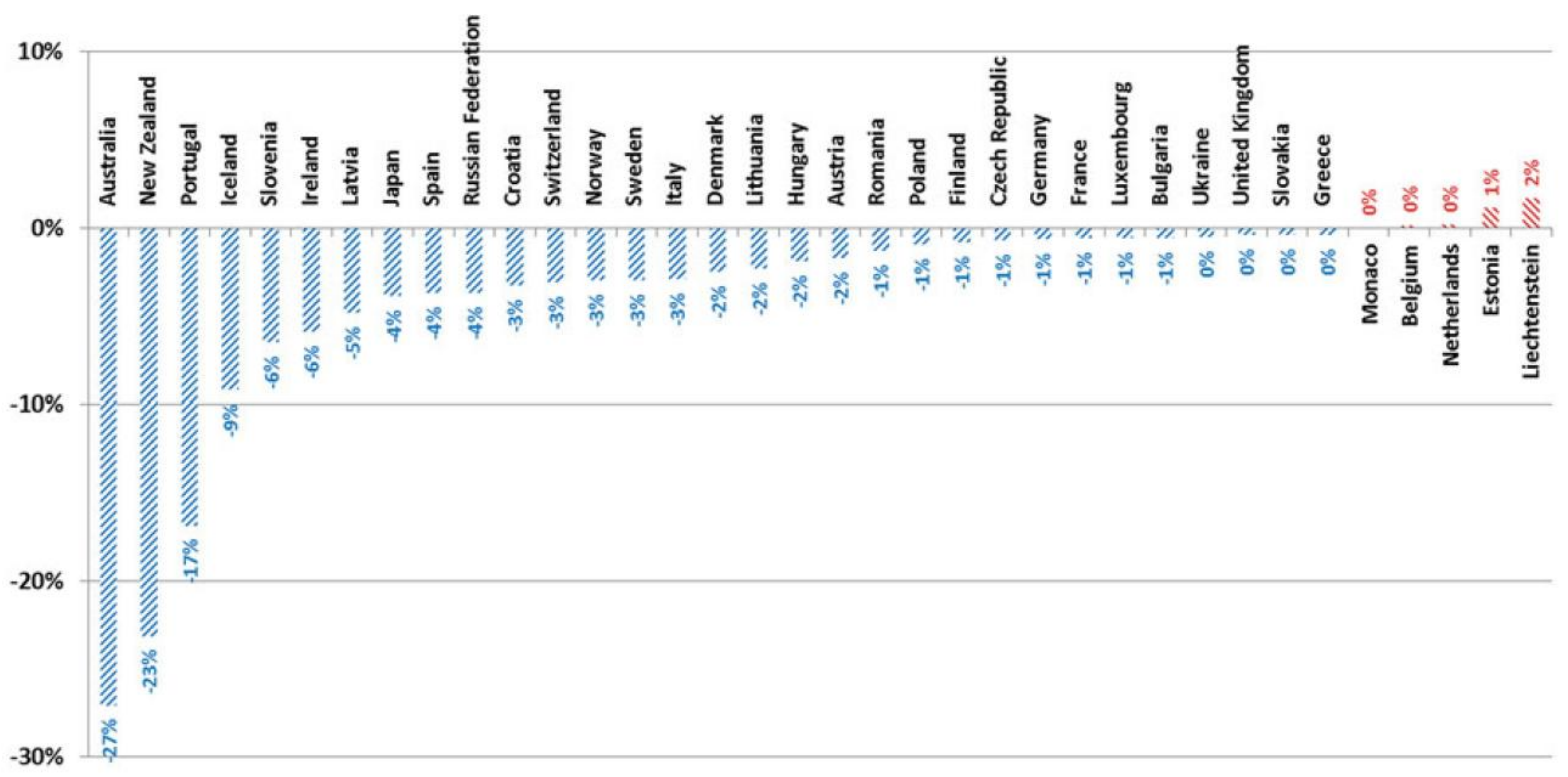

Source: authors' calculations based on the final annual review reports as published by the UNFCCC on 10 July

2015.

While the aggregate impact of LULUCF accounting on the overall balance of the Kyoto Protocol is limited, on an individual country level, articles 3.3 and 3.4 were game-changing for Italy, Slovenia and New Zealand. Indeed, these countries are in compliance with their Kyoto targets thanks to the integration of these rules. The impact of LULUCF accounting under articles 3.3 and 3.4 is beneficial for almost all countries, with the exception of Belgium, Netherlands, Estonia, Lichtenstein and Australia.

\section{A small contribution of flexibility mechanisms to target compliance}

Section 2.1 demonstrated that even though parties to the Kyoto Protocol achieved their aggregate emissions reduction target, some individual parties would not have been compliant domestically without the use of flexibility mechanisms. This section therefore reviews the use of the Kyoto flexibility mechanisms and different countries' strategies.

\subsection{Kyoto Protocol's flexibility mechanisms}

Besides the emissions reduction targets, the Kyoto Protocol incorporated so-called "flexibility mechanisms" primarily aimed at containing the cost of compliance: 
- "Bubbling" (article 4 of the Protocol) allows a group of Annex B countries to take a collective GHG emissions reduction commitment and then to share it among them, as it was done by the countries of the European Union (EU);

- Joint Implementation (JI, Article 6 of the Protocol) allows Annex B countries to offset their emissions by purchasing carbon credits resulting from projects in other Annex $B$ countries. Jl projects, thus, generate Emission Reduction Units (ERUs), which have to be converted from the AAUs of the host country. Therefore, JI does not affect the overall cap of Annex B countries, but only redistributes the emissions reduction efforts among them.

- The Clean Development Mechanism (CDM, Article 12 of the Protocol) allows Annex B countries to offset their emissions by investing into emissions reduction projects in non-Annex B countries that do not have emission caps. The CDM projects, thus, generate Certified Emission Reductions (CERs) - carbon credits that can be used by Annex B countries for compliance with their Kyoto targets in addition to their AAUs.

- International Emissions Trading (IET, Article 17 of the Protocol) allows Annex B countries to directly trade their AAUs. Thus, IET does not affect the total cap of Annex $B$ countries, but only redistributes the AAUs among them. AAU, CER and ERU transactions are overseen by the UNFCCC through the International Transaction Log (ITL).

\subsection{Balance of carbon units under the Kyoto Protocol by the end of the CP1}

In order to comply with their commitment under the Kyoto Protocol, Annex B countries must surrender the amount of carbon units - allowances or carbon credits - equivalent to their GHG emissions during the CP1. All carbon units are listed in national registries that publish annual reports, while the final verified emissions data for 2008-2012 has been available since 10 July 2015 (see Section 2).

These data show that no country lacked sufficient units for compliance as of the end of the true-up period, on 18 November 2015. However, Ukraine did not submit its true-up report, neither retired units for compliance while it holds more than enough units to do so. Thus, it is technically not in compliance with Kyoto Protocol's rules. 
The individual position of countries participating in the EU ETS shall be interpreted with caution as part of their units has been transferred to the European Union registry (Figure 5). Except Ukraine, all Annex B-2012 countries retired enough units and are therefore in full compliance with the Kyoto Protocol by the end of the CP1. Nevertheless, countries used different strategies to take benefit, or not, of their remaining units: some of these remaining units have been cancelled while others are being carried-over to the second commitment period (Figure 5).

Figure 5-Comparison of the use of units by countries excluding distributed AAUs used for domestic compliance

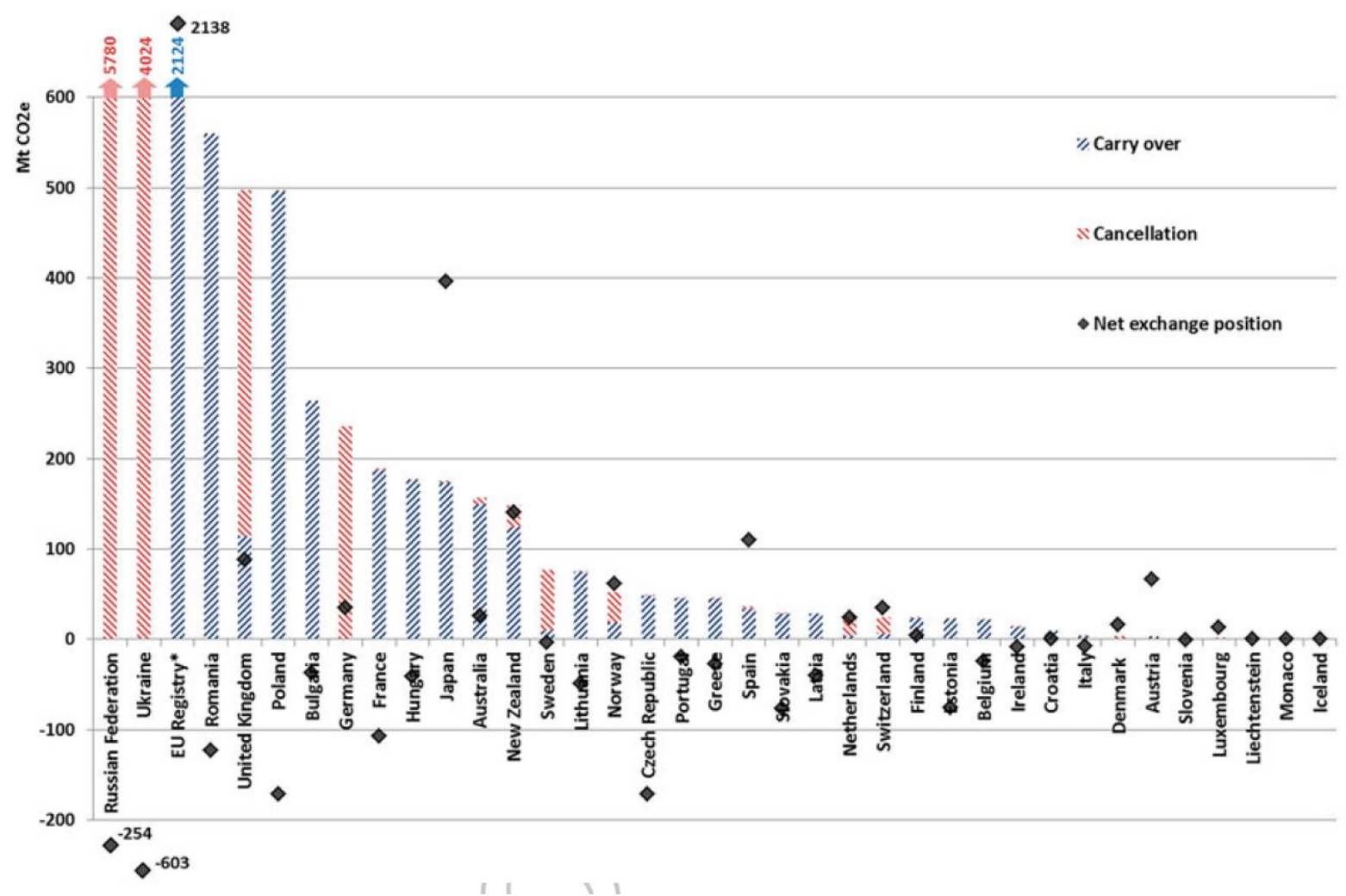

* The individual position of countries participating in the EU ETS shall be interpreted with caution as part of their units has been transferred to the European Union registry.

Notes:

This figure takes into account the operations recorded in countries' registries and makes the difference between units with a cost - either of opportunity or following a purchase of these units for compliance, a past benefit - i.e. units transferred to other countries, or a future benefit - i.e. units carried-over for the second commitment period and therefore that keep their intrinsic value. The amount of cancelled or lost units for Ukraine is calculated on the theoretical amount of units that Ukraine should have retired for compliance. 
The impact of regional and national ETSs on the emissions and carbon units' balance is twofold. First, under the EU ETS - that covers various Annex B countries - the cross-border exchange of an EU allowance (EUA) between two EU Annex B countries automatically implied the simultaneous exchange of an AAU. The trade of AAUs, which was theoretically reserved to countries and not for private entities, is therefore mainly driven by the private sector within the EU (see Section 3.3). Second, when a company surrenders a Kyoto credit under the EU ETS, the country "retires" the corresponding units and uses it for its own compliance under the Kyoto Protocol.

\subsection{Emissions trading under the Kyoto Protocol}

Emissions trading under the Kyoto Protocol can take the form of direct AAU trade or in the form of trading of carbon credits - ERUs that are backed by AAUs or CERs that are created ex-nihilo using the CDM mechanism (see Section 3.1). As of 1 January 2016 the 7,684 registered CDM and $604 \mathrm{JI}$ projects had issued 1,642 million CERs (of which 1,468 million for CP1 emissions reductions) and 864 million ERUs (all of them for CP1 emissions reductions) respectively (UNEP DTU 2015). Both CER and ERU supplies are largely concentrated in advanced developing countries and economies in transition respectively. Indeed, $85 \%$ of all issued CERs come from 4 largest CDM countries: China, India, South Korea and Brazil, while African countries account for less than $2 \%$. Similarly, over $90 \%$ of all issued ERUs come from Russia and Ukraine, while Western Europe accounts for only $3 \%$.

Japan, the EU and New Zealand were the major players in carbon trading under the Kyoto Protocol during the CP1. Indeed, these countries were the largest net importers of both emissions allowances and carbon credits. At the same time, they implemented different strategies to comply with their commitments.

Japan was the second largest GHG emitter after Russia among Annex B-2012 countries. Having adopted the emissions reduction target of $6 \%$ below the 1990 base year level, Japan was short of AAUs to cover its commitment and therefore had to resort to Kyoto flexibility mechanisms. Japan anticipated the need for units and steadily increased acquisition of AAUs, CERs and ERUs throughout the CP1. As soon as the end of 2013 Japan already held 150 million CERs and 22 million ERUs on its accounts. Additionally, the country has 
purchased 226 million AAUs (Ministry of Economy, Trade and Industry of Japan 2014). All these transfers were more than enough to cover Japan's initial lack of units.

A large share of these purchases were effectuated through private Japanese companies that may surrender Kyoto units under the Japanese Voluntary Scheme (World Bank 2012). Many of the acquisitions had occurred through so-called Green Investment Schemes (GISs) in cooperation with Czech Republic, Ukraine and Estonia. Under this scheme, Czech Republic, Ukraine and Estonia committed to invest the respective revenues into further domestic emissions reduction. The main objective of such arrangements was to prevent countries with large AAU surpluses from simply selling their "hot air" and to bolster the environmental integrity of carbon trading.

Even though some European countries may have needed to purchase units for compliance, the transactions within and towards the EU were mainly driven by the private sector. Indeed, the trading of carbon units is dominated by AAU transfers - as a result of EUA trading under the EU ETS. The main destination for carbon credit transfers were the EU-15 countries that purchased more than 1 billion CERs and ERUs (Figure 6).

New Zealand has been an active player on the carbon market since its ratification of the Kyoto Protocol in 2002, principally through the creation of a special framework: Projects to Reduce Emissions (PRE). The scheme encouraged voluntary early offset projects that could later be included into the $\mathrm{Jl}$ scheme and used in the New Zealand Emissions Trading Scheme (NZ ETS) that began operating in 2008 (Shishlov, Bellassen, and Leguet 2012). In addition, the NZ ETS allowed the use of international Kyoto credits facilitating the purchase of $90 \mathrm{Mt} \mathrm{CO}_{2} \mathrm{e}$ credits. 


\section{Figure 6 - Carbon trading flows as of 18 November 2015 (as \% of base-year emissions)}

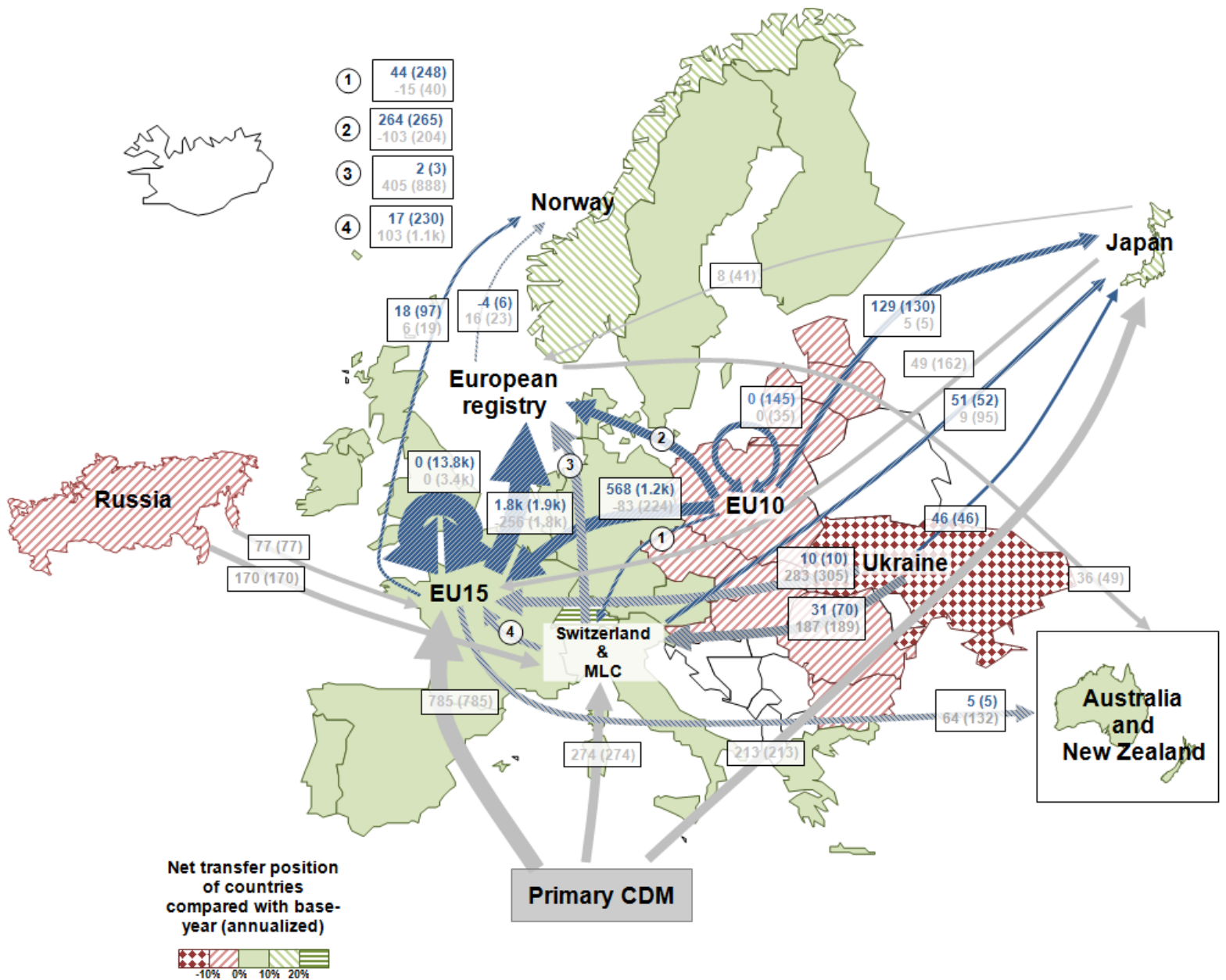

Notes: MLC: Monaco, Lichtenstein and Croatia. Flows of AAUs are in dark blue, flows of CERs/ERUs are in grey.

Figures in parentheses represent volumes traded in million tCO2e. Figures outside parentheses represent the net transfer. The direction of the arrow indicates the net transfer of all carbon units. A positive figure represents a net transfer in the same direction as the arrow.

E.g.: the volume of carbon units exchanged between EU15 countries and EU10 countries is 1.2 billion AAUs and 224 million CERs/ERUs. The net result of trades between these countries is that EU10 received 83 million CERs/ERUs from EU15 countries and EU15 countries received 568 million AAUs from EU10 countries.

Only exchange volumes higher than 40 million are represented. Iceland and Canada transferred units but for small amounts. Thus, these transfers are not represented.

Source: authors' calculations based on UNFCCC, national inventories and national registries data.

While Japan, the EU and New Zealand were the largest net importers of carbon units, Switzerland acted as a hub for carbon trading and an entry door for carbon credits in Europe. Indeed, the role of Switzerland is remarkable compared to its own emissions. Switzerland's trading volume represents 13 times its amount of initially received AAUs. Even the net position of the country is unusual with a surplus of more than one third of its base-year 
emissions. This may be explained by the fact that many CDM/JI project developers and carbon credit traders are located in Switzerland: they may currently hold the excess CERs that became un-sellable after the EU ETS demand dried up (Stephan, Bellassen, and Alberola 2014). The early connection of the Swiss registry with the International Transaction Log (ITL) has probably also played a role as it ensured delivery of the Kyoto credits to the national accounts of European investors before 2008 (Alberola and Stephan 2010).

\section{Conclusions}

This article provided an ex-post analysis of compliance of Annex B parties to the Kyoto Protocol during the CP1 (2008-2012). To this end primary data on national GHG emissions and exchanges in carbon units were analyzed. This analysis showed that among the 36 countries that fully participated to the CP1, only nine countries - Austria, Denmark, Iceland, Japan, Lichtenstein, Luxembourg, Norway, Spain and Switzerland - emitted higher levels of GHGs than committed under the Kyoto Protocol including Land-Use, Land-Use Change and Forestry (LULUCF). Their aggregate overshoot of the cap is only $36 \mathrm{Mt} \mathrm{CO}_{2} \mathrm{e}$ per year or less than 1\% of Annex B-2012 countries average annual emissions during the CP1. All in all however, Annex B-2012 countries over-complied with the Kyoto Protocol by $2.4 \mathrm{Gt} \mathrm{CO}_{2} \mathrm{e}$ per annum.

Of the possible explanations of this over-achievement, "hot-air" was estimated at $2.2 \mathrm{Gt}$ $\mathrm{CO}_{2} \mathrm{e}$ per annum, the participation of the USA and Canada would have added a net $1 \mathrm{Gt} \mathrm{CO}_{2} \mathrm{e}$ per annum of overshoot and LULUCF accounting rules further removed $0.4 \mathrm{Gt}_{\mathrm{CO}_{2} \mathrm{e} \text { per }}$ annum from the net result excluding LULUCF. None of these factors, some of which can be deemed illegitimate, would therefore on its own have led to global non-compliance, even without use of the $0.3 \mathrm{Gt} \mathrm{CO}_{2} \mathrm{e}$ of emissions reductions generated per annum by the CDM. The impact of domestic policies - not assessed here - should not be neglected either: within the scope of the EU ETS alone, it has been estimated to $0.1 \mathrm{Gt} \mathrm{CO}_{2} \mathrm{e}$ per annum (Gloaguen and Alberola, 2013).

Countries used flexibility mechanisms and Japan, the EU and New Zealand were the major net importers of carbon units during the CP1. Different countries implemented different strategies to comply with their commitments and to take benefit of flexibility mechanisms: directly purchasing carbon units, stimulating the domestic use of carbon credits by the 
private sector and incentivizing domestic emission reductions through different climate policies. Amongst them, the EU ETS is the largest example of national policy incentivizing both domestic emission reductions and the use of Kyoto credits. It has been the main driver of carbon units trading and the main source of demand for CERs and ERUs.

On the supply side, the largest net exporters of AAUs were Poland, Romania and Czech Republic. As to project-based carbon credits, they mostly originated from large developing countries - China, India, South Korea and Brazil account for $85 \%$ of issued CERs - and transition economies - Ukraine and Russia account for $90 \%$ of issued ERUs.

In a nutshell, we disentangled the quantitative legacy of the Kyoto Protocol, showing that it cannot be reduced to a single punchline such as "global compliance" or "hot air". We did not touched upon the qualitative legacy of the Protocol, which may be worth a separate assessment. While it may be difficult to establish a direct causal link between the Kyoto Protocol and domestic climate policies, the international climate agreement has likely boosted policies at national and regional levels. In addition, the procedures and human capital produced by the Kyoto Protocol, in particular in the field of Monitoring, Reporting and Verification - rebranded as "transparency" in the Paris Agreement - are valuable assets used by all sorts of climate mitigation tools and policies around the world.

\section{Bibliography}

Alberola, E., and N. Stephan. 2010. "Carbon Funds in 2010: Investment in Kyoto Credits and Emission Reductions." Climate Report No.23. CDC Climat. http://www.cdcclimat.com/Climate-Report-no23-Carbon-funds.html.

Barrett, S. 1998. "Political Economy of the Kyoto Protocol." Oxford Review of Economic Policy 14 (4): 20-39.

Böhringer, C. 2000. "Cooling down Hot Air: A Global CGE Analysis of Post-Kyoto Carbon Abatement Strategies." Energy Policy 28 (11): 779-89.

Bolin, B. 2008. A History of the Science and Politics of Climate Change. Cambridge University Press.

Boyd, E., N. Hultman, J. Timmons Roberts, E. Corbera, J. Cole, A. Bozmoski, J. Ebeling, et al. 2009. "Reforming the CDM for Sustainable Development: Lessons Learned and Policy Futures." Environmental Science \& Policy 12 (7): 820-31.

Branger, F., P. Quirion, and Julien Chevallier. 2013. "Carbon Leakage and Competitiveness of Cement and Steel Industries under the EU ETS: Much Ado about Nothing." 53-2013. Working Paper. Nogent-sur-Marne, France: CIRED. 
Castro, P., and A. Michaelowa. 2008. "Empirical Analysis of Performance of CDM Projects." Climate Strategies. http://www.climatestrategies.org/component/reports/category/39/138.html.

Ellerman, A. Denny, Frank J. Convery, and Christian de Perthuis. 2010. Pricing Carbon: The European Union Emissions Trading Scheme. Cambridge University Press.

Gloaguen, O., and E. Alberola. 2013. "Assessing the Factors behind CO2 Emissions Changes over the Phases 1 and 2 of the EU ETS: An Econometric Analysis." Working Paper 2013-15. CDC Climat.

Gupta, J., P. van Beukering, H. van Asselt, W.P. van der Gaast, and F. de Jong. 2008. "Clean and Sustainable? An Evaluation of the Contribution of the Clean Development Mechanism to Sustainable Development in Host Countries." 310. IOB Evaluations.

Haya, B. 2009. "Measuring Emissions Against an Alternative Future: Fundamental Flaws in the Structure of the Kyoto Protocol's Clean Development Mechanism." Working Paper. University of California, Berkeley.

Haya, B., and P. Parekh. 2011. "Hydropower in the CDM: Examining Additionality and Criteria for Sustainability." Working Paper, the Energy and Resources Group. University of California, Berkeley. http://erg.berkeley.edu/working_paper/2011/Haya\%20Parekh2011-Hydropower\%20in\%20the\%20CDM.pdf.

Kander, Astrid, Magnus Jiborn, Daniel D. Moran, and Thomas O. Wiedmann. 2015. "National Greenhouse-Gas Accounting for Effective Climate Policy on International Trade." Nature Climate Change 5 (5): 431-35. doi:10.1038/nclimate2555.

Kollmuss, A., L. Schneider, and V. Zhezherin. 2015. "Has Joint Implementation Reduced GHG Emissions? Lessons Learned for the Design of Carbon Market Mechanisms." Stockholm Environment Institute. http://www.seiinternational.org/mediamanager/documents/Publications/Climate/SEI-WP-2015-07Jl-lessons-for-carbon-mechs.pdf.

Lecocq, F., and P. Ambrosi. 2007. "The Clean Development Mechanism: History, Status, and Prospects." Review of Environmental Economics and Policy 1 (1): 134-51.

Manne, A., and R. Richels. 2004. "US Rejection of the Kyoto Protocol: The Impact on Compliance Costs and CO 2 Emissions." Energy Policy 32 (4): 447-54.

Ministry of Economy, Trade and Industry of Japan. 2014. "The National Registry System. Website." http://www.registry.go.jp/public_info_en.html.

Nordhaus, W., and J. Boyer. 1999. "Requiem for Kyoto: An Economic Analysis of the Kyoto Protocol." The Energy Journal, 93-130.

Peters, G., G. Marland, C. Le Quéré, T. Boden, J. Canadell, and M. Raupach. 2012. "Rapid Growth in CO2 Emissions after the 2008-2009 Global Financial Crisis." Nature Climate Change 2 (1): 2-4.

Sartor, O. 2012. "Carbon Leakage in the Primary Aluminium Sector: What Evidence after $61 / 2$ Years of the EU ETS?" 2012-12. Working Paper. Paris, France: CDC Climat Research.

Schiermeier, Q. 2012. "Hot Air." Nature 491 (7426): 656-58. 
Schleicha, J., W. Eichhammera, U. Boedea, F. Gagelmanna, E. Jochema, B. Schlomanna, and H-J. Ziesingb. 2001. "Greenhouse Gas Reductions in Germany - Lucky Strike or Hard Work?" Climate Policy 1 (3): 363-80.

Schneider, L. 2007. "Is the CDM Fulfilling Its Environmental and Sustainable Development Objectives? An Evaluation of the CDM and Options for Improvement." Report Prepared for the World Wildlife Foundation. Berlin: Öko-Institut. November.

- - . 2009. "Assessing the Additionality of CDM Projects: Practical Experiences and Lessons Learned." Climate Policy 9 (3): 242-54. doi:10.3763/cpol.2008.0533.

Shishlov, I., and V. Bellassen. 2012. "10 Lessons from 10 Years of the CDM." Climate Report No.37. CDC Climat.

- - . 2015. "Review of the Experience with Monitoring Uncertainty Requirements in the Clean Development Mechanism." Climate Policy.

Shishlov, I., V. Bellassen, and B. Leguet. 2012. "Joint Implementation: A Frontier Mechanism within the Borders of an Emissions Cap." Climate Report No.33. CDC Climat.

Stephan, N., V. Bellassen, and E. Alberola. 2014. "Use of Kyoto Credits by European Industrial Installations: From an Efficient Market to a Burst Bubble." Climate Report No.43. CDC Climat.

UNEP DTU. 2015. “CDM/JI Pipeline Databases.” United Nations Environment Programme. http://www.cdmpipeline.org/.

UNEP Risoe. 2014. "CDM/JI Pipeline Databases." United Nations Environment Programme. http://www.cdmpipeline.org/.

Wara, M.W., and D.G. Victor. 2008. "A Realistic Policy on International Carbon Offsets." Working Paper. PESD. http://iis-db.stanford.edu/pubs/22157/WP74_final_final.pdf.

Warnecke, C. 2014. "Can CDM Monitoring Requirements Be Reduced While Maintaining Environmental Integrity?" Climate Policy, 1-24. doi:10.1080/14693062.2014.875285.

Weyant, J., and J. Hill. 1999. "The Costs of the Kyoto Protocol." The Energy Journal (Special Issue).

World Bank. 2012. "State and Trends of the Carbon Market." Report. Washington: World Bank.

- - 2014. "State and Trends of Carbon Pricing." http://wwwwds.worldbank.org/external/default/WDSContentServer/WDSP/IB/2014/05/27/0004 56286_20140527095323/Rendered/PDF/882840AROREPLA00EPI2102680Box385232. pdf.

Zhenchuk, M. 2012. "The Integrity of Joint Implementation Projects in Ukraine." National Ecological Centre of Ukraine. http://en.necu.org.ua/files/2012/11/JIUkrainian_IntegrityStudy_en.pdf. 


\section{Appendix - GHG emissions data by country in 2008-2012 (source: authors'}

calculations based on the final annual review reports as published by the UNFCCC on 10 July 2015)

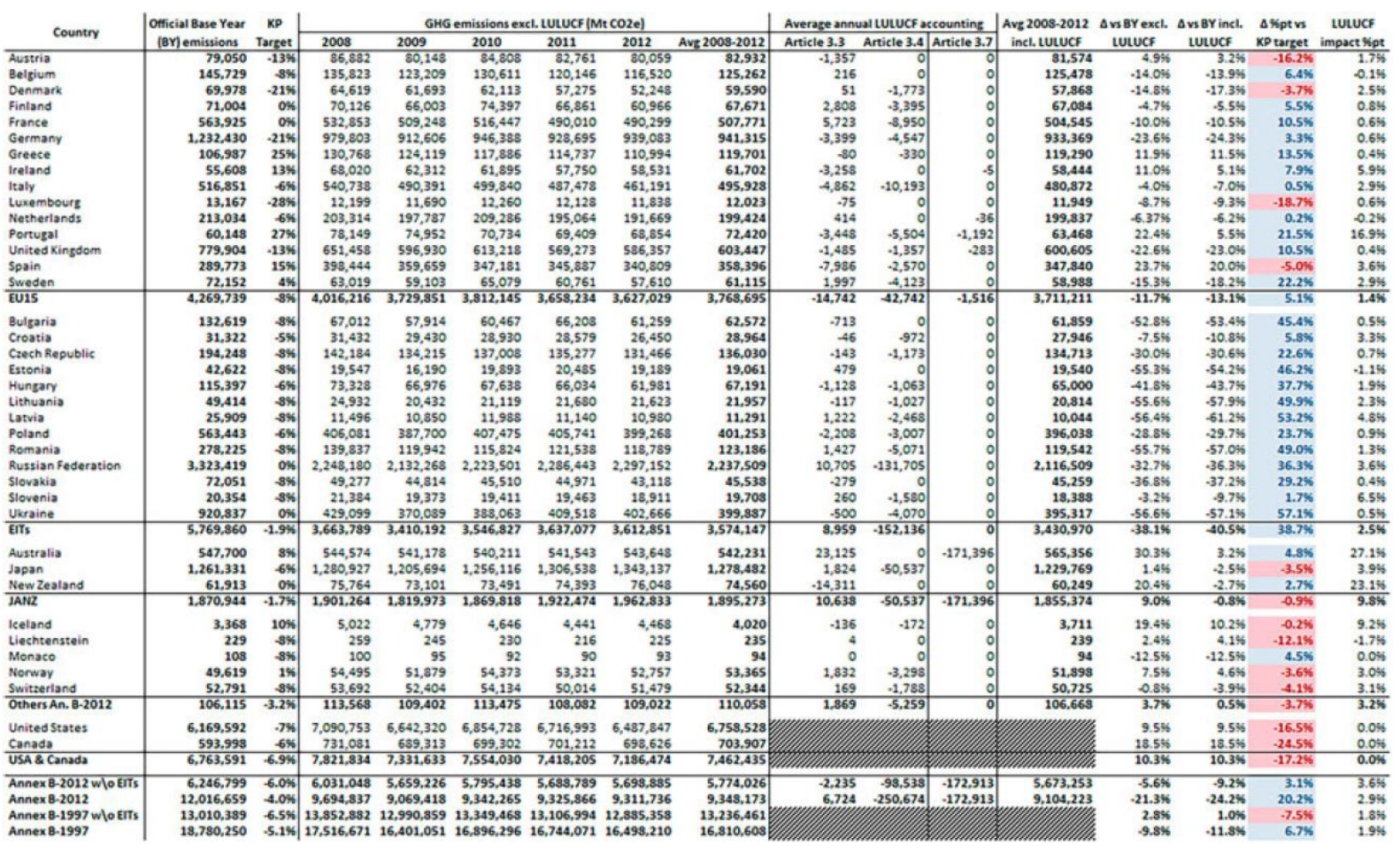

Notes: Decision 14/CP.7 which allows Iceland to subtract part of emissions coming from large installations.

Therefore, individual reported years are extracted for Inventory reports without taking into account decision $14 / C P .7$ while the average emission is the final figure that counts for compliance.

As they are not part of the Kyoto Protocol, USA and Canada did not report LULUCF with KP rules. Therefore LULUCF is not taken into account for these countries.

Article 3.7 of the Protocol allows voluntary countries to take into account LULUCF for the calculation of the base-year. This table shows the impact for these countries in terms of equivalent emission reductions. 